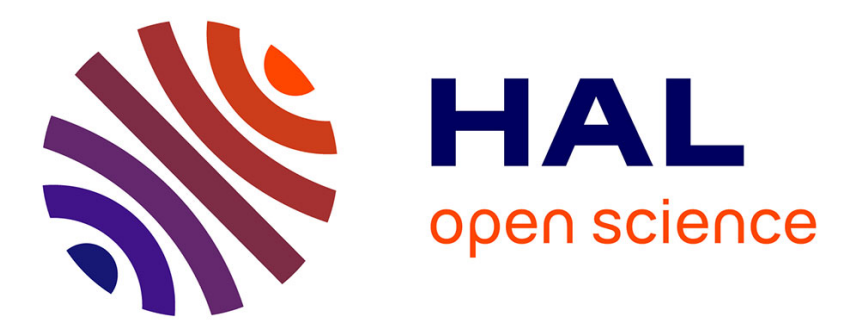

\title{
Psychosocial work factors and sleep problems: findings from the French national SIP survey
}

Emilie Chazelle, Jean-François Chastang, Isabelle Niedhammer

\section{To cite this version:}

Emilie Chazelle, Jean-François Chastang, Isabelle Niedhammer. Psychosocial work factors and sleep problems: findings from the French national SIP survey. International Archives of Occupational and Environmental Health, 2016, 89 (3), pp.485-495. 10.1007/s00420-015-1087-1 . hal-01288630

\section{HAL Id: hal-01288630 \\ https://hal.sorbonne-universite.fr/hal-01288630}

Submitted on 16 Mar 2016

HAL is a multi-disciplinary open access archive for the deposit and dissemination of scientific research documents, whether they are published or not. The documents may come from teaching and research institutions in France or abroad, or from public or private research centers.
L'archive ouverte pluridisciplinaire HAL, est destinée au dépôt et à la diffusion de documents scientifiques de niveau recherche, publiés ou non, émanant des établissements d'enseignement et de recherche français ou étrangers, des laboratoires publics ou privés. 
Psychosocial work factors and sleep problems: findings from the French national SIP survey

Emilie Chazelle ${ }^{1,2}$, Jean-François Chastang ${ }^{1,2}$, Isabelle Niedhammer ${ }^{1,2}$

1 INSERM, UMR_S 1136, Pierre Louis Institute of Epidemiology and Public Health, Department of social epidemiology, F-75013, Paris, France

2 Sorbonne Universités, UPMC Univ Paris 06, UMR_S 1136, Pierre Louis Institute of Epidemiology and Public Health, Department of social epidemiology, F-75013, Paris, France

\section{Correspondence to:}

Dr. Isabelle Niedhammer

INSERM UMRS 1136 - IPLESP - Team 7 (ERES)

Faculté de Médecine Pierre et Marie Curie - pôle Saint-Antoine

27 rue de Chaligny

F-75012 Paris, France

Email: isabelle.niedhammer@inserm.fr

Word count of abstract: 229

Word count: 4124

44 references

1 Figure

4 Tables 


\section{ABSTRACT}

Objectives This study aimed at exploring the cross-sectional and prospective associations between psychosocial work factors and sleep problems.

Methods The study population consisted of a national representative sample of the French working population (SIP survey). The sample sizes were 7506 and 3555 for the crosssectional and prospective analyses. Sleep problems were defined by either sleep disturbances or insufficient sleep duration at least several times a week. Psychosocial work factors included classical (job strain model factors) and emergent factors (recognition, insecurity, role/ethical conflict, emotional demands, work-life imbalance, etc.). Occupational factors related to working time/hours and physical work environment were also included as well as covariates related to factors outside work. Statistical analyses were performed using weighted Poisson regression analysis.

Results In the cross-sectional analyses, psychological demands, low social support, low recognition, emotional demands, perception of danger, work-life imbalance and night work were found to be associated with sleep problems. In the prospective analyses, psychological demands and night work were predictive of sleep problems. Using a less conservative method, more factors were found to be associated with sleep problems. Dose-response associations were observed showing that the more frequent the exposure to these factors, the higher the risk of sleep problems. No effect of repeated exposure was found on sleep problems.

Conclusion Classical and emergent psychosocial work factors were associated with sleep problems. More prospective studies and prevention policies may be needed.

Keywords: psychosocial work factors; occupational factors; sleep problems; sleep disturbances; insufficient sleep duration; cross-sectional analyses; prospective analyses; doseresponse associations 


\section{Introduction}

Sleep disorders, and insomnia as one of the leading disorders, are very common diseases in Western countries. In European countries, the prevalence of people reporting at least one symptom of insomnia has been estimated to be $34.5 \%$ and $6.6 \%$ satisfied the DSM-IV requirement for positive and differential diagnosis in the general population (Ohayon \& Reynolds, III, 2009). Sleep disorders have an important burden for health and a strong socioeconomic impact (Daley, Morin, LeBlanc, Gregoire \& Savard, 2009). Indeed, sleep disorders have been found to be associated with mortality and various health outcomes such as cardiovascular diseases, and also with accidents including home, car and work accidents, and absenteeism (Akerstedt, Fredlund, Gillberg \& Jansson, 2002a; Cappuccio, D'Elia, Strazzullo \& Miller, 2010; Daley, Morin, LeBlanc, Gregoire, Savard \& Baillargeon, 2009; Leger, Bayon, Ohayon, Philip, Ement, Metlaine et al. 2014; Schwartz, McDowell, Cole, Cornoni-Huntley, Hays \& Blazer, 1999; Uehli, Mehta, Miedinger, Hug, Schindler, HolsboerTrachsler et al. 2014).

The literature is seldom on potential occupational risk factors of sleep disorders; one exception may be working hours, especially night/shift work, and their impact on sleep (Akerstedt, Fredlund, Gillberg \& Jansson, 2002b). The identification of occupational risk factors and prevention towards these factors may be crucial. Psychosocial work factors in association with sleep disorders have been studied rarely in the literature and mainly through the classical job strain model by Karasek (Karasek, Brisson, Kawakami, Houtman, Bongers \& Amick, 1998), including psychological demands, decision latitude (or control) and social support, as well as the two combined situations, job strain (combination between high demands and low latitude) and iso-strain (combination between low support -isolation- and strain). A literature review using prospective and intervention studies on the associations between psychosocial work factors and sleep provided evidence for the associations of psychological demands and low control with poor sleep quality (Van Laethem, Beckers, Kompier, Dijksterhuis \& Geurts, 2013). This review provided inconclusive results for other psychosocial work factors, the number of high-quality studies being insufficient. Nevertheless, the authors of this review suggest that using all prospective studies (not only high-quality prospective studies), there may be moderate evidence for the effects of low social support, effort-reward imbalance and organizational injustice on sleep. Studies, that were not all prospective, found that low reward (Eriksen, Bjorvatn, Bruusgaard \& Knardahl, 2008; 
Fahlen, Knutsson, Peter, Akerstedt, Nordin, Alfredsson et al. 2006; Kim, Kim, Min, Min, Hwang \& Park, 2011; Kudielka, Von Känel, Gander \& Fischer, 2004), role conflict (Eriksen et al., 2008; Knudsen, Ducharme \& Roman, 2007), emotional demands (Park, Nakata, Swanson \& Chun, 2013), job insecurity (Kim et al., 2011; Park et al., 2013) or work-family conflicts (Lallukka, Ferrie, Kivimaki, Shipley, Sekine, Tatsuse et al. 2014; Lallukka, Rahkonen, Lahelma \& Arber, 2010; Park et al., 2013) were associated with sleep outcomes. These factors may be considered as emergent psychosocial work factors in association with sleep outcomes.

As a substantial part of the studies were cross-sectional, included workers from specific populations (particular work sectors, companies or occupations) and/or explored a limited number of psychosocial work factors, the proof levels on the effects of psychosocial work factors, especially those that are not from the job strain model, on sleep need to be improved.

The objectives of this study were to examine the associations of a large set of psychosocial work factors with sleep problems, taking well-known risk factors of sleep disorders into account. Innovative aspects of the study included the study of a large national representative sample of the working population, the analysis of cross-sectional and prospective data, the exploration of the job strain model factors and other understudied factors for the measurement of psychosocial work factors, and the study of frequency and duration of exposure. The study was designed as an etiological study aiming at exploring the associations of psychosocial work factors on the development of sleep problems.

\section{Methods}

Study sample

The study was based on the data from the national representative SIP (Santé et Itinéraire Professionnel) survey, conducted by the French Ministries of Labour (DARES) and Health (DRESS), the French Centre for Employment Studies (CEE) and the French National Institute for Statistics and Economic Studies (INSEE). The main objective of the survey was to provide information about the occupational determinants of health in the national French population (Coutrot, Rouxel, Bahu, Herbet \& Mermilliod, 2010). The SIP survey is a cohort study of a national representative sample of the French general population aged 20-74 years old in 2006. 
The survey was based on a face-to-face questionnaire at respondent's home. The first interview took place in 2006 and the response rate was $76 \%$, leading to an initial sample of 13648 people. The sample was followed up from 2006 to 2010 and interviewed again in 2010. Previous studies by our team have already been published using these data (Lassalle, Chastang \& Niedhammer, 2015; Malard, Chastang \& Niedhammer, 2015a; Malard, Chastang \& Niedhammer, 2015b; Murcia, Chastang \& Niedhammer, 2013; Murcia, Chastang \& Niedhammer, 2015; Niedhammer \& Chastang, 2014; Niedhammer, Malard \& Chastang, 2015). The SIP survey was approved by the French Ethics Committees (CNIL and CNIS).

\section{Sleep problems}

Sleep problems were assessed using two variables, sleep disturbances and insufficient sleep duration in 2006 and 2010. Sleep disturbances, i.e. difficulty initiating or maintaining sleep, or premature awakening, were assessed by the following item: 'Within the last twelve months, have you experienced sleep disturbances (difficulty falling asleep, night awakenings, premature awakening without being able to return to sleep): never/seldom, several times a month, several times a week, almost every day?' People who answered several times a week or almost every day were classified as cases of sleep disturbances. Sleep duration was assessed by the following item: 'Within the last twelve months, the number of your sleep hours during night has been: always/almost sufficient, insufficient several times a month, insufficient several times a week, insufficient almost every day?' People who answered having an insufficient number of sleep hours several times a week or almost every day were considered as having an insufficient sleep duration. People with either sleep disturbances or insufficient sleep duration at least several times a week were considered as cases of sleep problems in our analyses. The definition criteria of insomnia from the DSM-V reporting that 'the sleep difficulty occurs at least three nights a week' was followed to define the cases for sleep problems.

Psychosocial work factors and other occupational factors (Appendix)

Twelve psychosocial work factors were measured:

- Classical factors: psychological demands, decision latitude, and social support at work as 3 proxies for the job strain model dimensions (Karasek et al., 1998), 
- Emergent factors: recognition and job insecurity as two proxies of the sub-dimensions of reward (esteem and job insecurity) in the effort-reward imbalance model (Siegrist, Starke, Chandola, Godin, Marmot, Niedhammer et al. 2004), role conflict, ethical conflict, emotional demands, job performance, tensions with the public, perception of danger at work and work-life imbalance.

Although the focus was on psychosocial work factors, the study also included other occupational factors that were:

- Working time/hours variables: long working hours, night work, shift work and predictability of schedules.

- Occupational exposures of biomechanical, physical and chemical nature, and assemblyline work or repetitive work under time constraint.

For all items, the response categories were always/often/sometimes/never. Items were summed when the factors included more than one item. Three measures of exposure were used:

- $\quad$ binary variables in 2006: exposed versus non-exposed using the median cut-offs,

- frequency variables in 2006: using the initial response categories, always/often/sometimes/never, for the factors with one item or quartiles for those with more than one item, and

- $\quad$ repeated exposure evaluated using the binary variables in 2006 and 2010 for each occupational factor.

As the results were very close between binary and frequency variables, we chose to present the results of frequency variables only in our tables (except for the study of repeated exposures).

\section{Covariates}

The covariates, measured in 2006, included: age, occupational groups, marital status, presence of child(ren) $<3$ years old, social support outside work ( 2 items, instrumental and emotional support), life events during childhood i.e. before 18 years old (12 items) and life events within the four last years (4 items).

Statistical methods 
Weights were calculated using marginal calibration and inverse probability weighting to provide estimates representative of the population in 2006 (De Riccardis, 2012). Two sets of weights were used in the analyses: in the cross-sectional analysis, a first set of weights was used to control for a potential bias related to non-response in 2006, and in the prospective analysis, a second set of weights was used to control for potential biases related to nonresponse in 2006 and attrition in 2010. A marginal calibration on age, work status (working/unemployed/non-working)xage, urban area, size of household, occupation and economic activity was performed on the sample in 2006. Homogeneous response groups were formed based on characteristics in 2006 (work status, urban area, age, level of education, gender and self-reported health), and the probability of being interviewed in 2010 was calculated for each group. Weights calculated by marginal calibration (for non-response in 2006) were multiplied by the inverse probability of being interviewed in 2010. Finally, a second marginal calibration on territorial unit, urban area, agexgender, education, nationality, and size of household was performed on the sample of individuals interviewed in 2006 and 2010 to be representative of the population of 2006. All analyses were performed including weights.

A description of the study sample in 2006 was performed and a comparison was done between genders using Rao-Scott Chi-Square test.

The associations between occupational factors and sleep problems were studied using crosssectional and prospective data among the total sample of men and women. The cross-sectional analyses were performed using the data of 2006 for all variables (occupational factors, covariates and sleep problems) among the sample of those who were working in 2006. The prospective analyses were performed using the data of 2006 (occupational factors and covariates) and 2010 (sleep problems) among the sample of those who were working in both 2006 and 2010 and were free of sleep problems in 2006.

The associations between occupational factors and sleep problems, with adjustment for covariates, were studied using weighted Poisson regression analysis. Two types of models were performed: to study each factor separately with adjustment for covariates (models 1), and to study all factors simultaneously with adjustment for covariates (model 2). No collinearity was detected in these last models. 
The binary variables of occupational factors were used first. In model 2, interaction terms between psychological demands and decision latitude were introduced to test Karasek's hypothesis of job strain. Interaction terms were also tested one by one in model 2 between gender and each factor to explore potential differences in the associations between genders. To explore dose-response associations, analyses were performed using the frequency of exposure and repeated exposure to occupational factors. The analysis of the frequency of exposure was done using the frequency variables as continuous variables and trend tests were performed to explore potential linear associations in both cross-sectional and prospective analyses. This analysis aimed at exploring whether the risk of sleep problems increased with the frequency of exposure. The prospective analysis of repeated exposure was performed using the exposures of 2006 and 2010 (binary variables) simultaneously and an interaction term between these two exposures was added to test whether the effect of exposure in 2010 was the same or different according to the values of the exposure in 2006 . This analysis aimed at exploring whether repeated exposure in both 2006 and 2010 increased the risk further compared to the exposure in 2010 alone.

Sensitivity analyses were performed including additional covariates that were: employment variables, job change and unemployment/inactivity periods between 2006 and 2010, overcommitment at work as a personality factor, health status, alcohol/tobacco consumption, and life events between 2006 and 2010. Finally, a sensitivity analysis including all people at follow-up whatever their working status in 2010 (and not only those who were working) was also performed.

The statistical analyses were performed using SAS and STATA.

\section{Results}

Description of the study sample

Among the 13648 people of the initial sample from the general population, 7506 people were working at the time of the interview in 2006. People with an organic sleep disorder (narcolepsy, bruxism, restless leg syndrome, obstructive or central sleep apnea, excessive daytime sleepiness) were not included $(n=34)$. This sample of 7506 workers was used for the 
cross-sectional analysis. Among them, 6251 people were followed up in 2010 (follow-up rate: $83 \%)$. For the prospective analysis, people with sleep problems at baseline in $2006(n=1932)$ and people who were not working at the time of the survey in $2010(n=764)$ were excluded from the study. Thus, the study sample included 3555 workers for the prospective analysis (Figure 1). The description of the cross-sectional sample is provided in Table 1, and gender differences were observed for sleep problems, occupational factors and covariates. The prevalence of sleep problems was $27.66 \%$ for men and $33.73 \%$ for women, with a significant difference between genders. Sleep disturbances and insufficient sleep duration were strongly associated, confirming the interest of studying them together.

Cross-sectional analysis

In models 1, when each factor was studied separately, the frequency of exposure to occupational factors displayed significant linear associations with sleep problems, except job performance (Table 2). In model 2 with all factors studied simultaneously, the risk of sleep problems increased with the frequency of exposure to psychological demands, low social support, low recognition, emotional demands, perception of danger, work-life imbalance and night work. One interaction term with gender was significant: the association of psychological demands with sleep problems was stronger for men than for women.

Prospective analysis

Significant linear prospective associations were observed between the frequency of exposure to high psychological demands, low decision latitude, low recognition, ethical conflict, worklife imbalance and night work and sleep problems in models 1 (Table 3). The risk of sleep problems also increased with the frequency of exposure to biomechanical exposure and assembly-line work. In model 2, the risk of sleep problems increased with the frequency of exposure to psychological demands and night work. No interaction was found with gender.

Table 4 shows the results for the analysis of repeated exposure. As no significant interaction was found between exposure in 2006 and exposure in 2010, these interaction terms were not kept in the models (Table 4). No factor in 2006 was predictive of sleep problems in models 1 and 2 (one exception was low decision latitude). Almost all psychosocial work factors in 2010 were associated with sleep problems in models 1 (except decision latitude, social support, role 
conflict and job performance), and it was also the case in model 2 for psychological demands, emotional demands, work-life imbalance and night work with sleep problems. Biomechanical exposure also displayed a significant dose-response association with sleep problems.

Finally, no interaction term between psychological demands and decision latitude was found to be significant in both cross-sectional and prospective analyses.

\section{Discussion}

Main findings

In the cross-sectional analyses with all factors studied simultaneously, psychological demands, low social support, low recognition, emotional demands, perception of danger, work-life imbalance and night work displayed dose-response associations with sleep problems. In the prospective analyses with all factors explored together, psychological demands and night work were predictive of sleep problems with dose-response associations. When each factor was studied separately (a less conservative method), more factors were found to be associated with sleep problems. Dose-response associations were observed showing that the more frequent the exposure to some factors, the higher the risk of sleep problems. No effect of repeated exposure was found on sleep problems.

Comparison with the literature

Regarding the dimensions of the job strain model, psychological demands were associated with sleep problems in both cross-sectional and prospective analyses in our study. Our results are in agreement with previous findings as demonstrated by the strong evidence reported in the literature review by Van Laethem et al. (Van Laethem et al., 2013). Low decision latitude was associated with sleep problems, especially in our models 1. Van Laethem et al. (Van Laethem et al., 2013) stated that there may be moderately strong evidence for the association between job control and sleep quality but also reported that a number of prospective studies did not find a significant effect of job control on sleep. Low social support was associated with sleep problems in our cross-sectional analyses. The review by Van Laethem et al. (Van Laethem et al., 2013) provided moderately strong evidence for the association between low social support and sleep quality. However, among the seven prospective studies reviewed, 
only one found a significant association and two others reported elements towards this association (for one outcome and not for all outcomes, and for maintenance of poor sleep quality).

Regarding the dimensions of the effort-reward imbalance model, low recognition as a proxy of esteem was associated with sleep problems in our study (except in models 2 in the prospective analysis). Previous studies (Eriksen et al., 2008; Fahlen et al., 2006; Kim et al., 2011; Kudielka et al., 2004) showed a significant association between low reward and various sleep outcomes; only one of these studies had a prospective design (Eriksen et al., 2008). Job insecurity was associated with sleep problems in models 1 in our cross-sectional analysis. Two previous studies reported an association between job insecurity and sleep outcomes in cross-sectional samples of Korean workers (Kim et al., 2011; Park et al., 2013).

Regarding emergent psychosocial work factors, we studied two factors related to role stressors, role conflict and ethical conflict, and they displayed significant associations with sleep problems in our models 1 . Some rare studies explored role conflict in association with sleep outcomes and found that it was associated with poor sleep in a Norwegian prospective study among nurses' aides (Eriksen et al., 2008), and with difficulty initiating sleep and nonrestorative sleep in a American cross-sectional study (Knudsen et al., 2007) but role conflict and role ambiguity were not associated with insomnia in a Japanese cross-sectional study among workers in a manufacturing company (Nakata, Haratani, Takahashi, Kawakami, Arito, Kobayashi et al. 2004). Emotional demands and tensions with the public were associated with sleep problems in our cross-sectional analysis. These findings are in line with the results by Park et al. (Park et al., 2013) who reported an association between emotional demands and work-related sleep problems in a cross-sectional sample of Korean workers. Work-life imbalance was found to be associated with sleep outcomes mostly in our cross-sectional analyses. Some rare studies found that work-life imbalance/conflicts were associated with sleep outcomes in cross-sectional samples of employees of the City of Helsinki (Lallukka et al., 2010) and Korean workers (Park et al., 2013), and in a prospective study using three British, Finnish and Japanese occupational cohorts (Lallukka et al., 2014). The factors of role stressors, emotional demands and work-life imbalance have been studied very rarely in association with sleep problems and would deserve more attention in future studies. Job performance and perception of danger were also studied in our study, but to our knowledge, no previous studies explored these factors. 
Our study reported dose-response associations between exposure frequency and sleep problems. No impact of repeated exposure on sleep problems was observed in our study. Only a few studies explored the associations between changes in psychosocial work factors and sleep outcomes. Akerstedt et al. (Akerstedt, Nordin, Alfredsson, Westerholm \& Kecklund, 2012) reported the effects of a change from low to high work demands and prolonged exposure to high demands on new cases of impaired sleep. De Lange et al. (de Lange, Kompier, Taris, Geurts, Beckers, Houtman et al. 2009) stated that cumulative exposure to a high-strain work environment (characterized by high job demands and low job control) was associated with elevated levels of sleep-related complaints.

Strengths and limitations of the study

The strengths of the study may be underlined. The study was based on a large national representative sample of the French working population with satisfactory response and follow-up rates. Furthermore, as weights were included in all statistical analyses, nonresponse and attrition were corrected, and the results may be generalized to the whole working population. We observed gender differences in the prevalence of occupational factors, covariates and sleep problems, but found a very small number of differences in the associations between psychosocial work factors and sleep problems (Niedhammer, SaurelCubizolles, Piciotti \& Bonenfant, 2000). A comparison was done between cross-sectional and prospective analyses. The cross-sectional analysis may provide information on the shortterm/acute effects of psychosocial work factors on sleep, although reverse causation may also be possible (Magnusson Hanson, Akerstedt, Naswall, Leineweber, Theorell \& Westerlund, 2011). This analysis had a higher statistical power because of a larger sample size than the prospective analysis. The prospective analysis may provide information on the long-term and/or chronic effects of psychosocial work factors on sleep, makes clear the temporal sequence between exposure and outcome and possible the study of new cases of sleep problems. Psychosocial work factors were examined including both classical concepts and emergent factors understudied in the literature. We were able to provide information about dose-response associations, as the risk of sleep problems increased with the frequency of exposure to psychosocial work factors. Furthermore, sensitivity analyses also found doseresponse associations between exposure to psychosocial work factors and the frequency of sleep problems. Two types of models were performed allowing to study the associations 
between psychosocial work factors and sleep using two approaches, the first one exploring each factor separately, and the second one exploring all factors together, i.e. independently of each other. The second approach may be considered conservative as there may be complex interrelations between factors, some factors being causes or consequences of other factors, and may lead to overadjustment (Rugulies, Aust \& Pejtersen, 2010). Other occupational factors and major covariates, considered as well-known risk factors of sleep outcomes, were taken into account, and their results were consistent with the literature, reinforcing the validity of our study. In particular, night work and long working hours were found to be associated with sleep problems in agreement with previous studies (Akerstedt et al., 2002b; Dahlgren, Kecklund \& Akerstedt, 2005; Nakashima, Morikawa, Sakurai, Nakamura, Miura, Ishizaki et al. 2011; Sekine, Chandola, Martikainen, Marmot \& Kagamimori, 2006; Virtanen, Ferrie, Gimeno, Vahtera, Elovainio, Singh-Manoux et al. 2009). Sensitivity analyses were performed to check the robustness of the results and provided similar results.

Some limitations deserve to be mentioned. The study design was prospective but the 4-year period may be too long to study the impact of psychosocial work factors on sleep outcomes, and may lead to an underestimation of the associations observed. Indeed, other authors (Akerstedt et al., 2012) suggested that the effects of exposure to psychosocial work factors on sleep may be shorter. A healthy worker effect may be suspected as workers developing sleep problems within the 4-year period may have left the labour market in 2010. A sensitivity analysis was performed including major changes in job and working conditions and long nonworking period(s) between 2006-2010 as additional covariates and the results were unchanged. Furthermore, a sensitivity analysis including all people at follow-up whatever their work status in 2010 (and not only those who were working) also provided similar results. Psychosocial work factors were not measured using validated questionnaires, leading to potential imprecision in the variables used (Fahlen, Peter \& Knutsson, 2004). However, other authors underlined the interest and validity to construct proxies (Karasek, Choi, Ostergren, Ferrario \& De, 2007). Some psychosocial work factors may have been neglected as they were not available in the survey, and may be important in the association with sleep, such as organizational injustice (Elovainio, Ferrie, Gimeno, De, Shipley, Brunner et al. 2009; Kim et al., 2011), threats and violence at work (Eriksen et al., 2008; Park et al., 2013), or bullying (Lallukka, Rahkonen \& Lahelma, 2011; Nakata et al., 2004; Niedhammer, David, Degioanni, Drummond, Philip \& 143 occupational physicians, 2009). No validated instrument to measure sleep problems was used. Sleep disturbances and insufficient sleep duration were strongly 
associated and the separate analysis of these two variables provided very similar results compared to those of the combined outcome presented in the tables. A reporting bias may have occurred as both exposure and outcome were based on self-report, leading to a potential overestimation of the associations observed. Some covariates may be missing, such as consumption of psychoactive substances (tea, coffee or illicit drugs) or environmental factors (noise).

\section{Conclusion}

Our findings highlight the role of psychosocial work factors, including emergent factors, in sleep problems. These psychosocial work factors may have short-term effects on sleep, and for some of them long-term effects. Among these factors, some classical factors may be mentioned such as psychological demands, as well as emergent factors like emotional demands, low recognition and work-life imbalance. More prospective studies may be needed to confirm our results and prevention policies oriented towards new psychosocial work factors should be intensified. 


\section{Acknowledgements}

The authors thank the members of the DARES, DREES, CEE and INSEE, and all the people who participated to the SIP survey and made this study possible.

\section{Funding}

French ministry of labour (DARES, grant no 2200727156).

\section{Conflict of interest}

The authors declare that they have no conflict of interest. 
Appendix. List of the studied occupational factors and their items

Classical psychosocial work factors:

- psychological demands (3 items, work under pressure, too many things to do, and excessive amount of work)

- decision latitude ( 2 items, freedom to decide how to do the work, and use of skills)

- $\quad$ social support at work (1 item, good relationships with colleagues)

Emergent psychosocial work factors:

- recognition (1 item, fair feedback on the work done)

- job insecurity (1 item, fear of job loss)

- role conflict (1 item, not being able to work following best practices)

- ethical conflict (1 item, exposure to unethical situations)

- emotional demands (1 item, hiding feelings at work)

- job performance (1 item, wage or promotion dependent on performance/productivity)

- tensions with the public (1 item, tensions with users, students, patients, customers, etc.)

- perception of danger at work (1 item, fear for his/her own safety or the safety of others)

- $\quad$ work-life imbalance (1 item: work in line with family life).

Working time/hours variables:

- long working hours ( 1 item, $\geq 48 \mathrm{~h} /$ week)

- $\quad$ night work (1 item, work hours between 12-5am)

- $\quad$ shift work (1 item, work on alternating shifts)

- predictability of schedules (1 item, irregular hours difficult to predict)

Other occupational exposures:

- biomechanical exposure (3 items, manual materials handling, other biomechanical constraints, and vibrations)

- physical exposure (2 items, loud noise and extreme temperatures)

- chemical exposure (1 item, exposure to dust, fume, chemical products or germs)

- assembly-line work or repetitive work under time constraint (1 item). 


\section{REFERENCES}

Akerstedt,T., Fredlund,P., Gillberg,M., \& Jansson,B. (2002a). A prospective study of fatal occupational accidents -- relationship to sleeping difficulties and occupational factors. $J$ Sleep Res., 11(1), 69-71.

Akerstedt,T., Fredlund,P., Gillberg,M., \& Jansson,B. (2002b). Work load and work hours in relation to disturbed sleep and fatigue in a large representative sample. J Psychosom.Res., $53(1), 585-588$.

Akerstedt,T., Nordin,M., Alfredsson,L., Westerholm,P., \& Kecklund,G. (2012). Predicting changes in sleep complaints from baseline values and changes in work demands, work control, and work preoccupation--the WOLF-project. Sleep Med, 13(1), 73-80.

Cappuccio,F.P., D'Elia,L., Strazzullo,P., \& Miller,M.A. (2010). Sleep duration and all-cause mortality: a systematic review and meta-analysis of prospective studies. Sleep, 33(5), 585592.

Coutrot,T., Rouxel,C., Bahu,M., Herbet,J.B., \& Mermilliod,C. (2010). Parcours professionnel et état de santé. Premières Informations et Premières Synthèses, 1.

Dahlgren,A., Kecklund,G., \& Akerstedt,T. (2005). Different levels of work-related stress and the effects on sleep, fatigue and cortisol. Scand.J.Work Environ.Health, 31(4), 277-285.

Daley,M., Morin,C.M., LeBlanc,M., Gregoire,J.P., \& Savard,J. (2009). The economic burden of insomnia: direct and indirect costs for individuals with insomnia syndrome, insomnia symptoms, and good sleepers. Sleep, 32(1), 55-64.

Daley,M., Morin,C.M., LeBlanc,M., Gregoire,J.P., Savard,J., \& Baillargeon,L. (2009). Insomnia and its relationship to health-care utilization, work absenteeism, productivity and accidents. Sleep Med, 10(4), 427-438.

de Lange,A.H., Kompier,M.A., Taris,T.W., Geurts,S.A., Beckers,D.G., Houtman,I.L., \& Bongers,P.M. (2009). A hard day's night: a longitudinal study on the relationships among job demands and job control, sleep quality and fatigue. J Sleep Res, 18(3), 374-383.

De Riccardis,N. (2012). Traitements de la non-réponse et calages pour l'enquête santé et itinéraire professionnel de 2010. Direction de la recherche, des études, de l'évaluation et des statistiques - DREES, Document de Travail - Série Sources et Méthodes 36 (Septembre).

Elovainio,M., Ferrie,J.E., Gimeno,D., De,V.R., Shipley,M., Brunner,E.J., Kumari,M., Vahtera,J., Marmot,M.G., \& Kivimaki,M. (2009). Organizational justice and sleeping problems: The Whitehall II study. Psychosom.Med, 71(3), 334-340.

Eriksen,W., Bjorvatn,B., Bruusgaard,D., \& Knardahl,S. (2008). Work factors as predictors of poor sleep in nurses' aides. Int.Arch.Occup.Environ.Health, 81(3), 301-310.

Fahlen,G., Knutsson,A., Peter,R., Akerstedt,T., Nordin,M., Alfredsson,L., \& Westerholm,P. (2006). Effort-reward imbalance, sleep disturbances and fatigue. Int.Arch.Occup.Environ.Health, 79(5), 371-378. 
Fahlen,G., Peter,R., \& Knutsson,A. (2004). The Effort-Reward Imbalance model of psychosocial stress at the workplace - a comparison of ERI exposure assessment using two estimation methods. Work \& Stress, 18(1), 81-88.

Karasek,R., Brisson,C., Kawakami,N., Houtman,I., Bongers,P., \& Amick,B. (1998). The Job Content Questionnaire (JCQ): an instrument for internationally comparative assessments of psychosocial job characteristics. J.Occup.Health Psychol., 3(4), 322-355.

Karasek,R., Choi,B., Ostergren,P.O., Ferrario,M., \& De,S.P. (2007). Testing two methods to create comparable scale scores between the Job Content Questionnaire (JCQ) and JCQ-like questionnaires in the European JACE Study. Int.J Behav.Med, 14(4), 189-201.

Kim,H.C., Kim,B.K., Min,K.B., Min,J.Y., Hwang,S.H., \& Park,S.G. (2011). Association between job stress and insomnia in Korean workers. J Occup Health, 53(3), 164-174.

Knudsen,H.K., Ducharme,L.J., \& Roman,P.M. (2007). Job stress and poor sleep quality: Data from an American sample of full-time workers. Soc Sci.Med, 64(10), 1997-2007.

Kudielka,B.M., Von Känel,R., Gander,M.-L., \& Fischer,J.E. (2004). Effort-reword imbalance, overcommitment and sleep in a working population. Work \& Stress, 18(2), 167178.

Lallukka,T., Ferrie,J.E., Kivimaki,M., Shipley,M.J., Sekine,M., Tatsuse,T., Pietilainen,O., Rahkonen,O., Marmot,M.G., \& Lahelma,E. (2014). Conflicts between work and family life and subsequent sleep problems among employees from Finland, Britain, and Japan. Int J Behav.Med, 21(2), 310-318.

Lallukka,T., Rahkonen,O., \& Lahelma,E. (2011). Workplace bullying and subsequent sleep problems--the Helsinki Health Study. Scand J Work Environ Health, 37(3), 204-212.

Lallukka,T., Rahkonen,O., Lahelma,E., \& Arber,S. (2010). Sleep complaints in middle-aged women and men: the contribution of working conditions and work-family conflicts. $J$ Sleep Res., 19(3), 466-477.

Lassalle,M., Chastang,J.F., \& Niedhammer,I. (2015). Working conditions and psychotropic drug use: Cross-sectional and prospective results from the French national SIP study. $J$ Psychiatr.Res.

Leger,D., Bayon,V., Ohayon,M.M., Philip,P., Ement,P., Metlaine,A., Chennaoui,M., \& Faraut,B. (2014). Insomnia and accidents: cross-sectional study (EQUINOX) on sleep-related home, work and car accidents in 5293 subjects with insomnia from 10 countries. J Sleep Res., 23(2), 143-152.

Magnusson Hanson,L.L., Akerstedt,T., Naswall,K., Leineweber,C., Theorell,T., \& Westerlund,H. (2011). Cross-lagged relationships between workplace demands, control, support, and sleep problems. Sleep, 34(10), 1403-1410.

Malard,L., Chastang,J.F., \& Niedhammer,I. (2015a). Changes in major depressive and generalized anxiety disorders in the national French working population between 2006 and 2010. J Affect.Disord., 178 52-59. 
Malard,L., Chastang,J.F., \& Niedhammer,I. (2015b). Changes in psychosocial work factors in the French working population between 2006 and 2010. Int Arch Occup Environ Health, $88(2), 235-246$.

Murcia,M., Chastang,J.F., \& Niedhammer,I. (2013). Psychosocial work factors, major depressive and generalised anxiety disorders: Results from the French national SIP study. $J$ Affect.Disord., 146(3), 319-327.

Murcia,M., Chastang,J.F., \& Niedhammer,I. (2015). Educational inequalities in major depressive and generalized anxiety disorders: results from the French national SIP study. Soc.Psychiatry Psychiatr.Epidemiol.

Nakashima,M., Morikawa,Y., Sakurai,M., Nakamura,K., Miura,K., Ishizaki,M., Kido,T., Naruse,Y., Suwazono,Y., \& Nakagawa,H. (2011). Association between long working hours and sleep problems in white-collar workers. J Sleep Res., $20(1 \mathrm{Pt} 1), 110-116$.

Nakata,A., Haratani,T., Takahashi,M., Kawakami,N., Arito,H., Kobayashi,F., \& Araki,S. (2004). Job stress, social support, and prevalence of insomnia in a population of Japanese daytime workers. Soc.Sci.Med., 59(8), 1719-1730.

Niedhammer,I., \& Chastang,J.F. (2014). Psychosocial work factors and first depressive episode: retrospective results from the French national SIP survey. Int Arch Occup Environ Health.

Niedhammer,I., David,S., Degioanni,S., Drummond,A., Philip,P., \& 143 occupational physicians (2009). Workplace bullying and sleep disturbances: findings from a large scale cross-sectional survey in the French working population. Sleep, 32(9), 1211-1219.

Niedhammer,I., Malard,L., \& Chastang,J.F. (2015). Occupational factors and subsequent major depressive and generalized anxiety disorders in the prospective French national SIP study. BMC.Public Health, 15(1), 1559.

Niedhammer,I., Saurel-Cubizolles,M.J., Piciotti,M., \& Bonenfant,S. (2000). How is sex considered in recent epidemiological publications on occupational risks? Occup Environ Med, 57(8), 521-527.

Ohayon,M.M., \& Reynolds,C.F., III (2009). Epidemiological and clinical relevance of insomnia diagnosis algorithms according to the DSM-IV and the International Classification of Sleep Disorders (ICSD). Sleep Med, 10(9), 952-960.

Park,J.B., Nakata,A., Swanson,N.G., \& Chun,H. (2013). Organizational factors associated with work-related sleep problems in a nationally representative sample of Korean workers. Int Arch Occup Environ Health, 86(2), 211-222.

Rugulies,R., Aust,B., \& Pejtersen,J.H. (2010). Do psychosocial work environment factors measured with scales from the Copenhagen Psychosocial Questionnaire predict register-based sickness absence of 3 weeks or more in Denmark? Scand J Public Health, 38(3 Suppl), 42-50.

Schwartz,S., McDowell,A.W., Cole,S.R., Cornoni-Huntley,J., Hays,J.C., \& Blazer,D. (1999). Insomnia and heart disease: a review of epidemiologic studies. J Psychosom.Res., 47(4), 313333. 
Sekine,M., Chandola,T., Martikainen,P., Marmot,M., \& Kagamimori,S. (2006). Work and family characteristics as determinants of socioeconomic and sex inequalities in sleep: The Japanese Civil Servants Study. Sleep, 29(2), 206-216.

Siegrist,J., Starke,D., Chandola,T., Godin,I., Marmot,M., Niedhammer,I., \& Peter,R. (2004). The measurement of effort-reward imbalance at work: European comparisons. Soc.Sci.Med., 58(8), 1483-1499.

Uehli,K., Mehta,A.J., Miedinger,D., Hug,K., Schindler,C., Holsboer-Trachsler,E., Leuppi,J.D., \& Kunzli,N. (2014). Sleep problems and work injuries: a systematic review and meta-analysis. Sleep Med Rev., 18(1), 61-73.

Van Laethem,M., Beckers,D.G., Kompier,M.A., Dijksterhuis,A., \& Geurts,S.A. (2013). Psychosocial work characteristics and sleep quality: a systematic review of longitudinal and intervention research. Scand J Work Environ Health, 39(6), 535-549.

Virtanen,M., Ferrie,J.E., Gimeno,D., Vahtera,J., Elovainio,M., Singh-Manoux,A., Marmot,M.G., \& Kivimaki,M. (2009). Long working hours and sleep disturbances: the Whitehall II prospective cohort study. Sleep, 32(6), 737-745. 
Figure 1 Flow diagram for the cross-sectional and prospective study samples

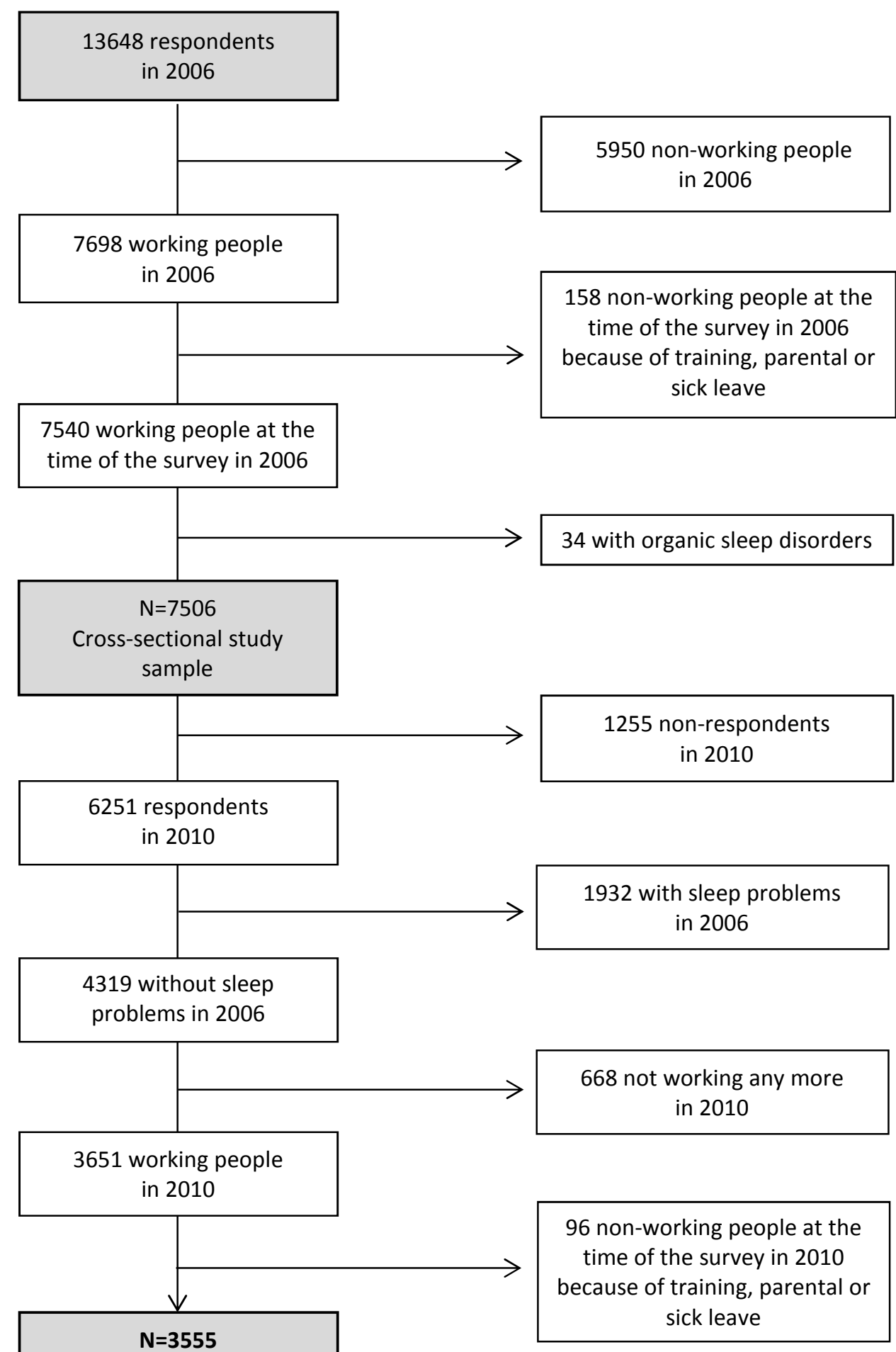

Prospective study sample 
Table 1 Description of the study sample according to sleep problems, covariates, and occupational factors in 2006

\begin{tabular}{|c|c|c|c|c|c|}
\hline & \multicolumn{2}{|c|}{$\begin{array}{c}\text { Men } \\
(\mathrm{N}=3686)\end{array}$} & \multicolumn{2}{|c|}{$\begin{array}{c}\text { Women } \\
(\mathrm{N}=3820)\end{array}$} & \multirow[t]{2}{*}{$\begin{array}{c}\mathrm{p}- \\
\text { value }\end{array}$} \\
\hline & $\mathrm{n}$ & $\%$ & $\mathrm{n}$ & $\%$ & \\
\hline Sleep problems & 1029 & 27.66 & 1307 & 33.73 & **** \\
\hline Age $(y)$ & & & & & $* *$ \\
\hline$<30$ & 463 & 16.96 & 450 & 16.98 & \\
\hline $30-39$ & 970 & 28.44 & 961 & 26.02 & \\
\hline $40-49$ & 1120 & 29.41 & 1255 & 30.24 & \\
\hline$\geq 50$ & 1133 & 25.20 & 1154 & 26.76 & \\
\hline Occupation & & & & & $* * *$ \\
\hline Managers, professionals & 634 & 18.37 & 501 & 12.46 & \\
\hline Associate professionals, technicians & 894 & 24.79 & 1019 & 25.05 & \\
\hline Clerks, service workers & 535 & 16.67 & 1884 & 49.76 & \\
\hline Manual workers & 1619 & 40.18 & 414 & 12.73 & \\
\hline Marital status (living alone) & 932 & 21.56 & 1217 & 25.00 & $* *$ \\
\hline Child(ren) under 3 years old & 385 & 12.84 & 308 & 10.11 & $* *$ \\
\hline Low social support outside work & 796 & 20.05 & 1003 & 25.03 & $* * *$ \\
\hline Life event(s) during childhood & 1710 & 46.03 & 1946 & 51.17 & $* * *$ \\
\hline Life event(s) within the last four years & 353 & 8.99 & 477 & 11.86 & $* * *$ \\
\hline \multicolumn{6}{|l|}{ Psychosocial work factors } \\
\hline High psychological demands & 1560 & 43.19 & 1438 & 36.86 & $* * *$ \\
\hline Low decision latitude & 1249 & 34.51 & 1290 & 34.14 & ns \\
\hline Low social support & 896 & 24.88 & 857 & 22.61 & ns \\
\hline Low recognition & 1151 & 31.89 & 1249 & 32.75 & ns \\
\hline Job insecurity & 853 & 23.88 & 811 & 21.39 & ns \\
\hline Role conflict & 1655 & 45.70 & 1797 & 46.37 & $* * *$ \\
\hline Ethical conflict & 1332 & 36.31 & 1153 & 29.74 & $* * *$ \\
\hline Emotional demands & 1255 & 35.97 & 1888 & 48.91 & $* * *$ \\
\hline Job performance & 2068 & 57.48 & 1521 & 40.52 & $* *$ \\
\hline Tensions with the public & 1494 & 42.19 & 1767 & 46.25 & $* * *$ \\
\hline Perception of danger & 1461 & 37.52 & 1088 & 28.84 & $*$ \\
\hline Work-life imbalance & 1123 & 32.37 & 1138 & 30.26 & ns \\
\hline \multicolumn{6}{|l|}{ Working time variables } \\
\hline Long working hours & 1534 & 42.76 & 827 & 21.26 & $* * *$ \\
\hline Night work & 897 & 24.58 & 377 & 9.98 & $* * *$ \\
\hline Shift work & 639 & 17.32 & 538 & 14.67 & $* *$ \\
\hline Low predictability & 1248 & 35.02 & 877 & 23.14 & $* * *$ \\
\hline \multicolumn{6}{|l|}{ Physical working conditions } \\
\hline Biomechanical exposure & 1626 & 42.87 & 1244 & 33.94 & $* * *$ \\
\hline Physical exposure & 1881 & 48.67 & 1013 & 27.14 & $* * *$ \\
\hline Chemical exposure & 1652 & 42.69 & 931 & 25.46 & $* * *$ \\
\hline Assembly-line work & 963 & 26.73 & 909 & 24.41 & ns \\
\hline
\end{tabular}


Table 2 Cross-sectional associations between occupational factors (frequency variables) and sleep problems in 2006: results of weighted Poisson regression analysis adjusted for covariates

\begin{tabular}{|c|c|c|c|c|}
\hline \multirow[t]{2}{*}{ Men and women $(\mathrm{N}=7495)$} & \multicolumn{4}{|c|}{ Sleep problems } \\
\hline & $\mathrm{RR}^{1}$ & $95 \% \mathrm{CI}$ & $\mathrm{RR}^{2}$ & $95 \% \mathrm{CI}$ \\
\hline \multicolumn{5}{|l|}{ Psychosocial work factors } \\
\hline High psychological demands & $1.25 * * *$ & $1.20-1.30$ & $1.10 * * *$ & 1.06-1.16 \\
\hline Low decision latitude & $1.07 * * *$ & 1.04-1.11 & 1.01 & $0.97-1.05$ \\
\hline Low social support & $1.19 * * *$ & 1.13-1.25 & $1.08 * *$ & 1.02-1.14 \\
\hline Low recognition & $1.16 * * *$ & $1.12-1.20$ & $1.06 * *$ & 1.02-1.11 \\
\hline Job insecurity & $1.14 * * *$ & 1.09-1.19 & 1.02 & $0.98-1.07$ \\
\hline Role conflict & $1.15 * * *$ & 1.10-1.20 & 1.01 & $0.96-1.06$ \\
\hline Ethical conflict & $1.23 * * *$ & 1.17-1.29 & 1.03 & 0.98-1.09 \\
\hline Emotional demands & $1.17 * * *$ & 1.13-1.21 & $1.08 * * *$ & 1.04-1.12 \\
\hline Job performance & 1.02 & $0.98-1.07$ & 0.99 & $0.94-1.03$ \\
\hline Tensions with the public & $1.18 * * *$ & 1.13-1.24 & 1.01 & $0.96-1.06$ \\
\hline Perception of danger & $1.22 * * *$ & 1.16-1.28 & $1.06 *$ & 1.01-1.13 \\
\hline Work life imbalance & $1.30 * * *$ & $1.25-1.35$ & $1.16 * * *$ & 1.11-1.21 \\
\hline \multicolumn{5}{|l|}{ Working time variables } \\
\hline Long working hours & $1.13 * *$ & 1.09-1.17 & 1.04 & $1.00-1.08$ \\
\hline Night work & $1.18 * * *$ & 1.12-1.23 & $1.10 * * *$ & 1.04-1.16 \\
\hline Shift work & $1.04 *$ & $1.00-1.08$ & 0.98 & 0.94-1.02 \\
\hline Low predictability & $1.11 * * *$ & 1.06-1.15 & 0.99 & $0.95-1.04$ \\
\hline \multicolumn{5}{|l|}{ Physical working conditions } \\
\hline Biomechanical exposure & $1.12 * * *$ & 1.08-1.16 & 1.02 & $0.98-1.06$ \\
\hline Physical exposure & $1.11 * * *$ & 1.07-1.15 & 1.02 & $0.98-1.06$ \\
\hline Chemical exposure & $1.09 * * *$ & 1.05-1.13 & 1.01 & $0.97-1.05$ \\
\hline Assembly-line work & $1.08 * * *$ & 1.04-1.12 & 1.01 & 0.97-1.05 \\
\hline \multicolumn{5}{|c|}{$\begin{array}{l}\text { The frequency variables of occupational factors were based on the initial coding for the factors with one item or on quartiles } \mathrm{fc} \\
\text { with more than one item } \\
\text { RR associated with an increase of } 1 \text { unit of the frequency variables } \\
\text { RR adjusted for gender, age, occupation, marital status, child under } 3 y \text {, social support outside of work, and life events } \\
{ }^{1} \text { Each occupational factor studied separately }{ }^{2} \text { All occupational factors studied simultaneously } \\
\text { In bold: RR significant at } 5 \% \\
* * *: p<0.001, * *: p<0.01, *: p<0.05\end{array}$} \\
\hline
\end{tabular}


Table 3 Prospective associations between occupational factors in 2006 (frequency variables) and sleep problems in 2010: results of weighted Poisson regression analysis adjusted for covariates

\begin{tabular}{|c|c|c|c|c|}
\hline \multirow[t]{2}{*}{ Men and women $(\mathrm{N}=3550)$} & \multicolumn{4}{|c|}{ Sleep problems } \\
\hline & $\mathrm{RR}^{1}$ & $95 \% \mathrm{CI}$ & $\mathrm{RR}^{2}$ & $95 \% \mathrm{CI}$ \\
\hline \multicolumn{5}{|l|}{ Psychosocial work factors } \\
\hline High psychological demands & $1.14 * * *$ & $1.06-1.23$ & $1.12 *$ & $1.03-1.21$ \\
\hline Low decision latitude & $1.08 * *$ & 1.02-1.15 & 1.04 & $0.98-1.12$ \\
\hline Low social support & 1.01 & $0.89-1.14$ & 0.93 & $0.81-1.06$ \\
\hline Low recognition & $1.11 * *$ & 1.04-1.19 & 1.07 & $0.99-1.16$ \\
\hline Job insecurity & 1.08 & $0.98-1.19$ & 1.02 & $0.92-1.12$ \\
\hline Role conflict & 1.06 & $0.96-1.16$ & 0.96 & $0.86-1.06$ \\
\hline Ethical conflict & $1.16 * *$ & 1.04-1.29 & 1.09 & $0.97-1.23$ \\
\hline Emotional demands & 1.03 & $0.97-1.09$ & 0.99 & $0.93-1.06$ \\
\hline Job performance & 1.00 & $0.92-1.08$ & 1.00 & 0.92-1.09 \\
\hline Tensions with the public & 1.04 & $0.94-1.15$ & 0.97 & $0.87-1.08$ \\
\hline Perception of danger & 1.10 & $0.99-1.22$ & 1.03 & $0.92-1.16$ \\
\hline Work life imbalance & $1.10 *$ & $1.00-1.22$ & 1.03 & $0.93-1.15$ \\
\hline \multicolumn{5}{|l|}{ Working time variables } \\
\hline Long working hours & 1.00 & $0.92-1.09$ & 0.98 & $0.89-1.07$ \\
\hline Night work & $1.24 * * *$ & 1.13-1.34 & $1.23 * * *$ & 1.11-1.35 \\
\hline Shift work & 1.05 & $0.98-1.13$ & 0.98 & $0.9-1.06$ \\
\hline Low predictability & 0.99 & $0.91-1.07$ & 0.94 & $0.86-1.03$ \\
\hline \multicolumn{5}{|l|}{ Physical working conditions } \\
\hline Biomechanical exposure & $1.07 *$ & $1.00-1.14$ & 1.05 & $0.97-1.13$ \\
\hline Physical exposure & 1.03 & $0.96-1.10$ & 0.98 & $0.91-1.06$ \\
\hline Chemical exposure & 1.02 & $0.95-1.10$ & 0.97 & $0.89-1.06$ \\
\hline Assembly-line work & 1.08* & $1.00-1.16$ & 1.03 & $0.95-1.11$ \\
\hline \multicolumn{5}{|c|}{$\begin{array}{l}\text { The frequency variables of occupational factors were based on the initial coding for the factors with one item or on quartiles } \\
\text { with more than one item } \\
\text { RR associated with an increase of } 1 \text { unit of the frequency variables } \\
\text { RR adjusted for gender, age, occupation, marital status, child under } 3 y \text {, social support outside of work, and life events } \\
\text { Rach occupational factor studied separately }{ }^{2} \text { All occupational factors studied simultaneously } \\
\text { In bold: RR significant at } 5 \% \\
* * * * \text { : }<0.001, * *: p<0.01, *: p<0.05\end{array}$} \\
\hline
\end{tabular}


Table 4 Prospective associations between occupational factors in 2006 and 2010 and sleep problems in 2010: results of weighted Poisson regression analysis adjusted for covariates

\begin{tabular}{|c|c|c|c|c|}
\hline \multirow{2}{*}{$\begin{array}{l}\text { Men and women }(\mathrm{N}=3550) \\
\text { RR }(95 \% \mathrm{CI})\end{array}$} & \multicolumn{4}{|c|}{ Sleep problems } \\
\hline & $\begin{array}{c}\text { Exposure } \\
\text { in } 2006-\mathrm{RR}^{1} \\
\end{array}$ & $\begin{array}{c}\text { Exposure } \\
\text { in } 2010-\mathrm{RR}^{1} \\
\end{array}$ & $\begin{array}{c}\text { Exposure } \\
\text { in } 2006-R^{2}\end{array}$ & $\begin{array}{c}\text { Exposure } \\
\text { in } 2010-\mathrm{RR}^{2} \\
\end{array}$ \\
\hline \multicolumn{5}{|l|}{ Psychosocial work factors } \\
\hline High psychological demands & $1.13(0.96-1.32)$ & $1.57 * * *(1.35-1.83)$ & $1.16(0.98-1.37)$ & $1.31 * * *(1.11-1.54)$ \\
\hline Low decision latitude & $1.21 *(1.03-1.41)$ & $1.13(0.97-1.32)$ & $1.20 *(1.02-1.40)$ & $1.00(0.85-1.18)$ \\
\hline Low social support & $0.96(0.80-1.15)$ & $1.17(1.00-1.37)$ & $0.91(0.76-1.09)$ & $1.01(0.86-1.18)$ \\
\hline Low recognition & $1.09(0.93-1.28)$ & $1.29 * *(1.11-1.50)$ & $1.07(0.90-1.26)$ & $1.11(0.95-1.30)$ \\
\hline Job insecurity & $1.05(0.88-1.26)$ & $1.21 *(1.02-1.44)$ & $0.99(0.83-1.18)$ & $1.07(0.90-1.27)$ \\
\hline Role conflict & $0.99(0.85-1.16)$ & $1.12(0.96-1.31)$ & $0.92(0.78-1.08)$ & $0.93(0.79-1.10)$ \\
\hline Ethical conflict & $1.09(0.93-1.28)$ & $1.35 * * *(1.16-1.58)$ & $1.06(0.90-1.25)$ & $1.15(0.98-1.35)$ \\
\hline Emotional demands & $0.94(0.80-1.10)$ & $1.56 * * *(1.33-1.82)$ & $0.92(0.78-1.07)$ & $1.30 * * *(1.11-1.52)$ \\
\hline Job performance & $1.07(0.92-1.25)$ & $0.91(0.79-1.07)$ & $1.05(0.91-1.22)$ & $0.87(0.75-1.01)$ \\
\hline Tensions with the public & $0.95(0.81-1.12)$ & $1.32 * * *(1.12-1.55)$ & $0.91(0.77-1.08)$ & $1.07(0.90-1.26)$ \\
\hline Perception of danger & $0.98(0.83-1.16)$ & $1.40 * * *(1.19-1.64)$ & $0.96(0.81-1.13)$ & $1.17(1.00-1.38)$ \\
\hline Work life imbalance & $1.02(0.86-1.21)$ & 1.45* (1.24-1.71) & $1.01(0.85-1.21)$ & $1.22 *(1.03-1.45)$ \\
\hline \multicolumn{5}{|l|}{ Working time variables } \\
\hline Long working hours & $0.92(0.75-1.12)$ & $1.27 *(1.05-1.53)$ & $0.87(0.71-1.07)$ & $1.07(0.88-1.31)$ \\
\hline Night work & $1.08(0.87-1.35)$ & $1.52 * * *(1.24-1.86)$ & $1.16(0.92-1.44)$ & $1.31 *(1.06-1.61)$ \\
\hline Shift work & $1.02(0.81-1.29)$ & $1.17(0.94-1.45)$ & $0.88(0.69-1.13)$ & $0.96(0.76-1.21)$ \\
\hline Low predictability & $0.95(0.79-1.14)$ & $1.18(0.99-1.40)$ & $0.87(0.72-1.05)$ & $0.97(0.81-1.16)$ \\
\hline \multicolumn{5}{|l|}{ Physical working conditions } \\
\hline Biomechanical exposure & $0.94(0.79-1.12)$ & $1.43 * * *(1.21-1.70)$ & $0.91(0.75-1.09)$ & $1.27 *(1.05-1.54)$ \\
\hline Physical exposure & $0.91(0.76-1.08)$ & $1.37 * * *(1.15-1.62)$ & $0.88(0.73-1.06)$ & $1.08(0.89-1.30)$ \\
\hline Chemical exposure & $0.93(0.77-1.12)$ & $1.20 *(1.00-1.44)$ & $0.90(0.74-1.09)$ & $1.06(0.88-1.29)$ \\
\hline Assembly-line work & $1.10(0.92-1.32)$ & $1.16(0.97-1.38)$ & $1.06(0.88-1.27)$ & $1.00(0.83-1.19)$ \\
\hline
\end{tabular}

